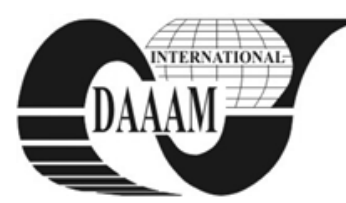

\title{
AN EXPERIMENT WITH ENHANCED LEARNING IN ENGINEERING EDUCATION
}

\author{
SVETSTKY, S[tefan]; MORAVCIK, O[liver]; STEFANKOVA, J[ana] \& SCHREIBER, P[eter]
}

\begin{abstract}
Knowledge represents a key element in a framework of any teaching and learning activity. Within the implementation of technology enhanced learning the preprogrammed desktop environment has been developed which enables a teacher or student a personalised working with knowledge. When using the environment a set of the informatics tools has been produced (e.g., Writing pad - standalone, elearning material, WEB-pages, templates, tests) and tested for active learning in the diverse courses of study. The first experiences showed that a various content (courses of study) requires a various approach and an informatics tools combination.
\end{abstract}

Key words: technology of enhanced learning, active learning, knowledge processing, informatics tools

\section{INTRODUCTION}

Knowledge represents a key element in a framework of any teaching and learning activity. Within the implementation of technology enhanced learning the pre-programmed desktop environment has been developed which enables a teacher or student to have a personalised working experience with knowledge. In this context, the desktop environment works as the "Batch Information and Knowledge Editor" (BIKE). At the beginning (Svetsky, 2007), the desktop environment was used at the detached university's workplace mostly in conditions analogical to blended and distance learning. Afterwards (Svetsky et al, 2008, 2010), by using the BIKE, the further off-line and online learning materials were created (tutorials, forums, e-libraries), including a set of outcomes. The pre-programmed environment that works on a teacher's computer enables him the building of both adaptive learning material and also the ability to select tailored informatics tools (programming codes, optional menus, and tailored applications).

\section{THE INFORMATICS SUPORT FOR ACTIVE LEARNING}

The teachers and bachelor's students, in general, need any personalised informatics tools applicable to information and knowledge processing. In addition, today's teacher or individual user must work on their computers with a huge amount of knowledge in conditions which are characterised by attributes such as multipurpose, multilingual, multiformat and multiwindow. This state-of-the-art automatically requires working with "knowledge packages" which are to be batch processed. In terms of this, however, an actual ICT tools level is too low, including software for personal computers. It must be emphasised that the BIKE is neither a learning/course management system nor content management one. This universal environment exploits "knowledge tables" for batch knowledge processing and provides for browsable outputs or study material (readable with common internet browsers). It also enables internet batch retrieving, text processing, and many other pre-programmed actions in order to enhance and automate teaching and learning. In this paper, there is not enough space to explain a basic principle of active learning. It must be noted that the main focus of the active learning techniques are aimed at the students (they do something). In addition, from a practical point of view, as mentioned in a page of California State University (Paulson, Faust, 2010), this reference describes approximately 30 techniques of active learning,, e.g., "One Minute Paper, Active Review Sessions, Concept mapping, Quotations". Thus, if we want to solve ICT support for active learning in general, we need engineering content (to be taught), students (learners), classrooms with computers (offline or/and online), and then we can select one or more from the 30 techniques. The core of the solution is then to investigate which steps in common active learning techniques are repeatable, and what can be "automated via computer".

In this context, the BIKE provides for a large "active" area with supporting elements, as a portfolio which can support students to be "cognitive active". From an informatics point of view, the system support for active learning is briefly illustrated in figure 1. As shown, such informatics support is based on the BIKE (as a database application) by which a large palette of outcomes can be produced in cooperation with the operating system (Windows), common browsers (Internet Explorer, OPERA), internet applications (php/mysql), and freeware or other commercial software (e.g. MS Office, Text To Speech applications within language support).

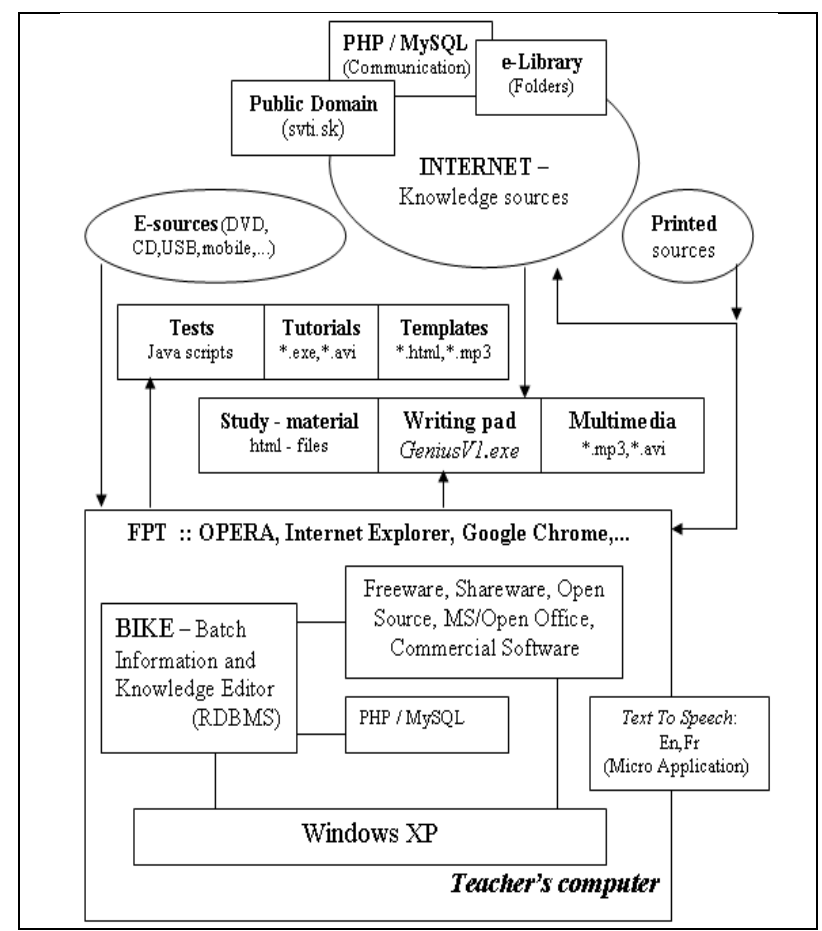

Fig. 1. The schema of the informatics support for active learning on a teacher's computer 


\section{THE IMPLEMENTATION OF ACTIVE LEARNING INTO ENGINEERING COURSES}

The developed informatics tools were tested in some engineering courses of study (Environmental protection Occupational health and safety - Semester projects I-II-III General Chemistry). In this case, the combination of the informatics tools was used by teachers and students for performing many tasks of technology enhanced learning. Some of them were also investigated as the "active elements" for active learning, especially for writing semester projects and works which included their language support.

It must be emphasised that the described informatics tools (scripts, menus, tailored applications) are different than other ones when using common learning course management systems (LCMS) or e-learning tools. In these tools, there are features preferred that are typical for file managers, Intranet or WEB 2.0 technologies, however, the BIKE or its stand-alone version Writing pad (geniusV1.exe) work as desktop applications on teachers' computers and on computers in the classroom.

Technology enhanced learning is based on two levels informatics (tools) and pedagogical (content). After providing the bachelor's students with the set of informatics tools the next steps were focused on content processing. The practice showed, from an active learning point of view, that the engineering content is especially important. If there is no pedagogical content appointed, then no action can be made by the students. Further, the practice also showed that if some computers in the classroom were online the bachelor's students did not concentrate enough on solving their tasks. They had a tendency to have unruly behaviour (e.g., they visited other WEB-sites on the Internet during teaching). Likewise, the students were not able to employ the tailored internet forums in an efficient manner although the forums were programmed for each course of study due to better feedback between teacher and students.

Naturally, these problems wouldn't have arisen in the case of simple computer aided support. For instance, the traditional method "one minute paper" can be simply performed by using a "forum". On the other hand, now, that there are developed informatics tools at our disposal one does not know which of them are convenient for active learning support. Thus, the generalisation was made that a shared element of the engineering's courses of study could be the semester work with fixed content. This was then unified with the MS Word template together with detailed off-line/online instructions, e.g., with document structure, how to write English and German abstracts, etc. Likewise, the directions for applying internet batch retrieving were given.

The first results showed that by comparison with the traditional active learning methods the other methods could be developed when applying the computer enhanced learning support. Such active learning can consist from the various methods, e.g., inclusion of batch retrieval when being applied by students within writing their semester works. For example, for batch retrieving, the five keywords were given in the Writing Pad, as follows: occupational health and safety - risk assessment machinery - glossary risk assessment - risk assessment ppt - OHSA risk assessment. The batch internet retrieval made by a stand - alone resulted into twenty opened windows within the OPERA browser

It must be also underlined, that the informatics skills of the bachelors students were not sufficient enough for using the selfdeveloped informatics tools. Thus, their testing in the classroom was very time consuming. Therefore, for the next development it is very important to prepare students for routine handling and mastering the informatics tools in order to process the pedagogical content within the required time for active learning. Likewise, they should enhance their skills for engineering content processing. With respect to this issue, a bilateral collaboration regarding ICT support was also performed (Divjak, Begicevic, Moravcik, Svetsky, 2010).

\section{CONCLUSION}

The set of the informatics tools has been developed within the implementation of personalised technology enhanced learning for engineering education at the Faculty of Materials Science and Technology of Slovak University of Technology. Some of these tools were selected and tested for active learning. Basically, there are two ways for the active learning informatics support.

Firstly, it can be selected for any common active learning technique and investigated as to which of the informatics tools within the BIKE (knowledge editor and generator) can be applied. For instance, if the "one minute paper" technique was chosen as the active learning method, then it would be automated by selecting the feedback forum from the menu of the active informatics tools.

However, such an approach has not been implemented in the field of ICT support yet, because the informatics tools commonly described and used are mostly internet applications focused on content management, or learning and course management systems (CMS, LMS, LCMS). In addition, only the technology - driven approach is preferred nowadays. Hence, they are not convenient for active learning support.

In context with this, many developed "active" informatics tools were tested for some engineering courses of study (used by approximately 200 students this year). The practice showed that the testing of issues such as the semester work writing, the reading room, the use of internet batch retrieving and multilingual support can result in an innovative active learning practice. This means that due to a synergic effect entirely new material and techniques can be created. It would not be possible to do it without computers (this is the second way for the active learning informatics support).

\section{REFERENCES}

Divjak, B.; Begicevic, N.; Moravcik, O.; Svetsky, S. (2010). Bilateral collaboration for ICT support in engineering education, Proceedings of the Joint International IGIPSEFI, Annual Conference 2010, Diversity unifies Diversity in Engineering Education, 19th - 22 th September 2010, Trnava, Slovakia, ISBN 978-2-87352-003-8, SEFI, Brussel

Paulson, D. R.; Faust, J. L. (2005). Active Learning For The College Classroom, Available from: http://www.calstatela.edu/dept/chem/chem2/Active/index.ht m Accessed: 2010-11-11

Svetsky, S. (2007). Modelling of Multilingual e-Learning and Virtual Learning space for R\&D Staff, Proceedings of the ICETA, $5^{\text {th }}$ International Conference on Emerging eLearning Technologies and Applications, Stara Lesna, Slovakia, 6th - 8th September 2007, ISBN 978-80-8086061-5, pp 1-4, Elfa, Kosice

Svetsky, S.; Moravcik, O.; Tanuska, P.; Rehakova, A.; Ruskova, A. (2008). Modelling of Multilingual e-Learning and Virtual Learning space for R\&D Staff, Proceedings of the ICETA, $6^{\text {th }}$ International Conference on Emerging eLearning Technologies and Applications, High Tatras, Slovakia, 11th - 13th September 2008, ISBN 978-80-8086089-9, pp 347-340, Elfa, Kosice

Svetsky, S.; Moravcik, O.; Tanuska, P. (2010). Some aspects of the technology enhanced learning in engineering education, Proceedings of the Joint International IGIP-SEFI, Annual Conference 2010, Diversity unifies - Diversity in Engineering Education, 19th - 22 th September 2010, Trnava, Slovakia, ISBN 978-2-87352-003-8, SEFI, Brussel 